JULIO ESTRADA

INSTITUTO DE INVESTIGACIONES ESTÉTICAS, UNAM

\title{
Revueltas: una música de naturaleza impura
}

\author{
De la asepsia a la escatología
}

$\mathrm{L}$ a cultura de la música que abandona su añejo vínculo con la poesía y se ofrece pura y de aire abstracto rebasa apenas medio milenio de existencia en Europa y las sociedades influidas por esta última y, como en otras tradiciones, servía más a los poderes religiosos o políticos que al disfrute del sonar per se. Bach, de quien el viejo mundo desprende las raíces más abstractas de su potencial musical, establece una clara colindancia entre dos ámbitos de la música, el que se nutre o el que prescinde del texto; mientras en la obra religiosa acentúa con el fondo armónico el drama cristiano que Lutero enarbola con la palabra, en la música pura la razón matemática aporta un paradigma artístico donde todo converge. Lo perfecto es aquí sustancial cuando Bach asume su obra dentro de la mente del Creador e invita a escuchar la elevación de la música, deber ser del juramento religioso que firma toda su obra: Soli Deo Gloria. ${ }^{\text {I }}$

Mozart emana de la nueva sociedad que a la mitad del siglo xvin observa a la emoción abrirse paso en música y, con o sin palabras, canta el amor en tono de comedia o entona la muerte en un drama nunca jamás eterno que pulsa en

I. Léase Lutero, su antecesor y coterráneo en Eisenach: "al lado de la palabra de Dios, sólo la música merece ser exaltada como dueña y reina de los sentimientos humanos. Cuando se agudiza y es pulida por el arte, se comienza a entender con asombro la gran sabiduría y perfección de Dios en su maravillosa obra de la armonía." Georg Rhau, Symphoniae iucundae, pref. Martín Lutero, Colección de 52 Motetes (Wittenberg: G. Phau, I538). 
la emoción humana, como la transparente transcripción del llanto y del duelo. El avance en la percepción de la naturaleza es imparable y con Beethoven se integra al arte musical la réplica de la catástrofe antes amenaza estética, ${ }^{2}$ con el bello vigor que copia al fresco el torbellino la Appasionatta: ahí el tono doliente de la música se escinde del oído colectivo y traza a solas la escucha inédita de acordes borrosos en el grave o de sonoridades cuya cercanía con el ruido exigen entender las pérdidas auditivas que le achacan desde I796, como narra en 1802 su prematuro testamento de Heiligenstadt. ${ }^{3}$

Aproximarse al abatimiento de Beethoven es irrecusable en el desvele del vínculo vida-obra, ${ }^{4}$ el cual obliga a explorar nuevas vetas auditivas que, con apoyo en la memoria y el ingenio constructivo, arman el talento creador de métodos que pronto devienen intrínsecos, según indicarían algunos de estos factores:

Acústico: ante el decline del oído, Beethoven refuerza la densidad en los graves con una perturbadora dilatación de la amplitud en detrimento de la claridad del espectro armónico; dicha apertura hacia la mayor permisividad sonora se concentra con mayor frecuencia en sonoridades de la escala menor armónica, de mayor combinatoria disonante que la de la escala diatónica y cuya energía amplifica la percepción del espectro.

Mnemónico: dentro de la misma escala menor armónica, el discurso se contrae a funciones básicas rayanas en lo obsesivo — desde el simple I-V-I hasta evoluciones como I-V-VI-VII $-\mathrm{I}_{6} /_{4}-\mathrm{V}_{7}-\mathrm{I}-\mathrm{y}$ la repetición a corto plazo deviene un elemento esencial del método compositivo;' el armado del tiempo a medio plazo recurre a procedimientos ventajosos para retener la materia, ahí donde la variación alcanza su más alto desarrollo y profundidad creativa.

2. Amadeo Estrada, "Furtwängler y las catástrofes", Perspectiva Interdisciplinaria de Música, núm. 2 (febrero, 2008): 79-85.

3. Véase http://es.wikipedia.org/wiki/Testamento de Heiligenstadt

4. Una muestra de ello es la división tripartita de su obra con el eje en la pérdida del oído, como se predica a mediados del siglo xIx. Véase Wilhelm von Lenz, Beethoven et ses trois styles, Music Reprint Series (Nueva York: Da Capo Press, I980 [1852]). La división propone las fechas de inicio de la producción hasta I802 para el primer periodo, de I803 a I8I4 para el medio y de I8I5 a I827 para el periodo tardío; el año I8O2 sirve para señalar la coincidencia con el testamento de Heiligenstadt, que ubica el inicio del padecimiento en I796.

5. Obsérvese cómo las aventuradas modulaciones cromáticas que emprende Mozart en obras como la Fantasía para piano en Do menor que requieren de gran justeza auditiva para captar evoluciones inéditas — por ejemplo, el paso de la dominante de RE al acorde de FA menor- no se producen en Beethoven y sólo reaparecen en la música de Schubert. 
Constructivo: el ensayo de reducir la carga mnemónica para concentrarse en microestructuras evolutivas parece conducir al motivo, nueva noción y nuevo recurso que simplifica y rebasa la noción de tema mediante la construcción repetitiva a corto plazo y a mínima distancia; como con la Quinta, el todo deja de acoplar elementos a largo plazo y deviene un ensamblaje de partículas que tiende a ordenarse dentro de distancias mínimas, con lo cual el autor reforzaría la información para dar apoyo a un oído débil. ${ }^{6}$

Aun cuando la sensatez de Beethoven mantiene en secreto su enfermedad para evitar la ironía ajena, no deja de exponer su psique a la percepción auditiva de otros; da el nombre de Patética a su octava sonata, opus I3, escrita en I798 a un par de años de iniciarse la sordera y transluce su consternación; escúchese el registro fonográfico de Edwin Fischer en 1938, quien desampara la resonancia del acorde inicial para convertirlo en referencia auditiva medular del primer movimiento - Grave, Allegro. El plomizo acorde en Do menor con que inicia el grave es el motivo más breve de la obra y su oscura densidad — cuatro teclas en el registro grave del bajo y tres por debajo del registro medio - se aleja de la armonía clásica y se proclama ruidoso; Beethoven escribe justo debajo del acorde un $f p$ — cuando podría aparecer por separado el signo de $p$ - y deja la incógnita al intérprete, quien tiene ahí dos vertientes: tocar débilmente la secuencia posterior al acorde o hacer lo que Fischer: aislar el ataque en un ictus al acometerlo con fuerza y en un gesto rápido retirar los dedos del teclado para colocarlos de nuevo en el mismo sitio y desfigurar la resonancia, o bien recurrir a una combinación de juego entre los pedales de retención y de sordina, todo ello producto de una concepción inédita de la articulación. 7 El complemento del acorde es un breve motivo melódico que asciende con esfuerzo, esquema que la partitura pide repetir - ataque y ascenso - aunque a partir del segundo hasta el cuarto acordes Fischer opta sólo por tocar el acorde fuerte con la resonancia natural y el ascenso débil (fig. I).

6. La idea de mínima distancia alcanza la música de los siglos xx y xxi; baste observar las evoluciones armónicas masivas de tipo continuo en la música cromática de Ligeti, más nubes sonoras que las evoluciones de tipo discontinuo propias de la estocástica en Xenakis. Véase Julio Estrada, Realidad e imaginación continuas. Filosofía, teoría y métodos de creación musical en el continuo (México: Universidad Nacional Autónoma de México-Instituto de Investigaciones Estéticas, en prensa).

7. Una y otra articulaciones son ajenas al piano de finales del siglo XVIII y sólo tienen eco en la creación para dicho instrumento hasta el xx; acaso el ambiente experimental en tiempos de Fischer influye para que integre un nuevo gesto o, lo que en Beethoven tendría aún más mérito, es él quien realiza el hallazgo al intentar hacer la copia del hundimiento de su oído. 

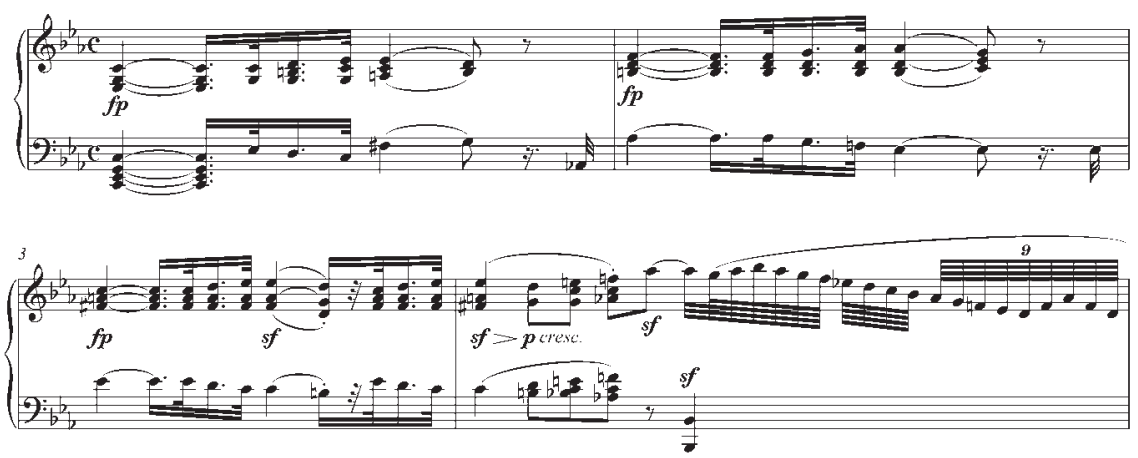

I.Beethoven, inicio de la Sonata núm. 8, opus I3, Patética.

El propio Fischer aborda su percepción del problema en un extenso estudio de las sonatas — en mi traducción_-: "El $f p$ del primer acorde ofrece una dificultad adicional; ¿debería tocarse $f$ [en el ataque] y dejarlo [enseguida] en $p$ hasta el final de la semicorchea con punto? Aunque es difícil reproducirlo hoy, es preferible recurrir al efecto orquestal del $f p$ porque coincide más con la idea de patética." 8

La articulación inicial a la cual recurre Fischer sería indeseable para finales del siglo XVIII, que procura obtener mayor resonancia del piano; la interpretación transgrede la pureza misma de la escritura y de la técnica e incita, o incluso somete al escucha mediante la paradoja acústica a la vivencia ineludible de lo privado, la sordera. El temprano aviso de pérdida de aquella energía que antes procuraba mayor resonancia armónica mediante el efecto de la sordina manual es premonición del deterioro. Cerca del final del Allegro di molto e con brio, una secuencia en ocho compases con ocho acordes largos hace recordar el acorde del inicio: un ciclo dramático de cuatro repeticiones enfáticas suena primero arriba y enseguida se precipita en un registro extremo del grave; de nuevo la estridencia procura mayor energía acústica y sirve a la resonancia armónica; mientras, la insistencia en el contraste agudo-grave parece denunciar con rabia el problema. El silencio entrelazado en los cuatro ascensos se confirma con mayor fuerza que nunca. El oído de Beethoven no alcanza el

8. E. Fischer, Beethoven's Pianoforte Sonatas, A Guide for Students \& Amateurs, trads. Stanley Godman y Paul Hamburger (Londres: Faber \& Faber, 1959), 47: "The $f p$ of the very first chord offers a further difficulty; should this be played $f$ to begin with and then the whole chord $p$ until the demisemiquaver? Difficult though it is to reproduce today, the orchestral effect of the $f p$ is to be preferred because it is more in accord with the idea of pathetique." 
indulto: al reiniciar el Grave al final del mismo movimiento, el sitio que antes ocupaba con violencia aquel denso acorde plomizo es ahora un silencio con igual duración: la oscuridad es total; a ésta sigue el ascenso esforzado del breve motivo melódico que se reduce al registro central-agudo. El acorde al inicio y su silencio hacia el final devienen con Fischer en un motivo que porta el drama: primero el oído herido, luego su ausencia. ${ }^{9}$

La revolución del universo subjetivo en Beethoven desboca en el romanticismo y deja presentir la modernidad que un siglo después deviene intimidad expresiva en la Viena de Freud que inaugura con Pierrot lunaire la primicia creadora del sueño al mismo tiempo que la escatología en París de Le sacre, descorche de tabúes e irrupción arquetípica de un ritmo de danza que masturba, fornica o viola. Antípodas musicales, Schoenberg y Stravinski son hermanos en lo atávico: el diván donde delira el inconsciente y es tálamo imaginario del desfogue sexual tiene en la habitación de al lado el lecho de la fertilidad, del nacimiento y de la muerte: nunca la música se alejó más de la pulcritud de su cuna para desembuchar con arrebato lenguajes reprimidos o secretos.

Pierrot el extravagante y el bárbaro Sacre son aún voces de un parto, frenesí psíquico y ritual que, oh paradoja, a poco de nacer se blindan uno con aires de cordura y otro con ínfulas de ecuanimidad. En I9I3, justo a un siglo de distancia de la Patética, Le sacre alumbra una nueva vivencia de percepción musical: el fagot desgarra su canto en el extremo agudo, los arcos extravían su rango y atizan las cuerdas, la percusión asesta un mare magnum granuloso de barullos, las melodías se encaraman en una trama de bullas ambiguas, los ritmos se atrancan en aglomeraciones turbulentas. La imagen de la música se atropella con un jaque que desmiembra melodía, armonía, contrapunto, ritmo, textura, forma o instrumentación para arruinar, al cabo, el equilibrio entre el tiempo y su memoria. ¿Cómo percibe Stravinski Le sacre antes de materializarse, cómo se escucha en la primera versión o cómo muta hasta su moderna interpretación? Conocer la evolución de cada uno de esos contrastes es imprescindible para transmitir la sustancia de la obra y su devastador efecto sobre la idea precedente de música: antes de la creación, auténticamente en la trastienda, Stravinski explora instrumentos, inventa su nuevo uso y predice una amalgama orquestal obtenida sólo in situ al ceñirse a un descubrimiento

9. Escúchense las interpretaciones de Edwin Fischer de la Sonata núm. 8 para piano en Do menor Patética op. I3: Adagio cantabile: http://www.youtube.com/watch?v=jIR28uUp6ow (I938) y Grave-Allegro di molto e con brio: http://www.youtube.com/watch?v=6aILDo7Youo 
que patentiza la caducidad de la técnica de composición musical amparada en lo escrito, con lo cual reabre la puerta del método creativo: percibir para imaginar. Al nacer la obra en el teatro de los Champs Élysées, brota un gallo que oprime en el extremo agudo al fagot, un bicho no a tono con su linaje; el hallazgo flamante del reencuentro con lo arcaico se planta en el legendario estreno del 29 de mayo y el anciano Saint-Saens abandona airado el sitio al enterarse de que el ruido es de un instrumento que ya no reconoce; mientras, Olivier Messiaen alude a la náusea y al vómito que a los cinco ańos le provoca la misma circunstancia cuando en su clase de análisis cuestionamos la tersura moderna de Le sacre frente a su consabida estridencia musical. Aun si algunas versiones recientes, como la de Claudio Abbado, se esmeran en dar autonomía a cada voz para revelar una textura heterofónica inadvertida por el apelmazamiento de las sonoridades individuales en grabaciones antiguas — escúchese Ansermet, referencia por décadas para Le sacre—, el pulimiento constante que sufre todavía la obra borra hasta el empalago el ardimiento original y trastoca su imagen en el objeto perfecto, indiferente al origen mítico e iniciático de la música.

La concepción de una obra se liga a su contacto inmediato con el mundo cuando el intérprete, primer apropiador público, traduce la abstracción de lo escrito y puede evocar al imaginario primigenio, que no cesa de plantear incógnitas a la mente que aspira acometer una nueva versión de la misma música; la certidumbre aquí no es por necesidad ventaja sino riesgo de olvidar todo aquello que da temple veraz al arte — recuerde el lector las primeras grabaciones de los pasajes sinfónicos de Brahms donde las cuerdas escalan lo más agudo con una fragilidad estrujante que desnuda posiblemente el anhelo expresivo original: el error es aparente porque transporta mayor sustancia que la afinación absoluta. En discrepancia con ello, en la historia musical del siglo xx predomina la negación del rastro subjetivo del proceso de creación para afirmar que la música sólo transmite sonidos — lo comprueban ejemplos tan distintos como Stravinski, Xenakis, Cage y Nancarrow-, y exige de la interpretación un purismo estético cuyo logro es la perfección del resultado; la estética de compositores e intérpretes expertos opta por la factura que no dé lugar a la ambigüedad y lleve a la certidumbre: del azar el menos dudoso y de los ruidos el menos ruidoso, y así mayor la impresión de destreza. En disconformidad con la profilaxis, el historicismo que intenta resucitar la música del barroco y del clásico durante la segunda mitad del siglo xx se obliga a asumir la imperfección cuando revive los dilemas que comparten la gesta 
de la obra: conocer la belleza germinal reside en omitir el filtro de la purificación — atiéndase a Mozart por fuera del piano moderno cuando Ronald Brautigam acomete el primer movimiento de la Sonata en LA menor, K. 3 Io (I778) y descubre al oído moderno la acústica ignorada de la escritura original, donde descuellan el contraste entre registros simultáneos o el hervidero en el grave producto del trémolo que oscila entre dos octavas. ${ }^{\text {IO }}$

La interpretación de una obra incluye por necesidad la historia de su aventura mental a través de la auscultación solitaria y codificación escrita previas al nacimiento y percepción de la obra concluida — "una obra terminada es eso", dice en Silence Cage-: ${ }^{\text {II }}$ la escritura es logro y fatalidad a la vez $-\mathrm{y}$ simulacro cuando se desconoce el proceso de búsqueda que al cabo la fija. En música, la evolución constante de los instrumentales abre espacios y a la vez borra las huellas esenciales del ayer, con lo cual el imperio de las reglas de juego con lo escrito deviene una obligación estética que aplasta la iniciativa de experimentar con la lectura ante signos insuficientes para satisfacer la exigencia hermenéutica.

La dimensión evocadora de lo musical es tan móvil e impredecible como esa subjetividad perceptiva que no deja de fusionar el todo: desde los sustratos de conocimiento de lo escrito en la partitura hasta los aspectos privados que mueve la obra en cada uno, esa mixtura nebulosa y compleja donde oído, sinestesia, memoria, intuición o saber musicales aproximan el proceso de creación al de recepción, ahí donde la vivencia de la música deviene mediante su percepción un ejercicio intransferible y recóndito que intenta a tientas comprender el todo.

Los hallazgos de intérpretes aislados que inventan la técnica para dar sentido a lo escrito — como Fischer - o un historicismo musical cuya inmersión avanza del Renacimiento al Romanticismo — del clavicémbalo de Gustav Leonhardt al pianoforte de Brautigam — revelan una fecundidad arrinconada por siglos en la música e incitan a considerar dicho ejercicio al ahondar en la música del siglo xx, como el ensayo de las páginas siguientes en un intento de aproximar al lector y al oyente futuro a observar la concordancia entre la vida de Silvestre Revueltas y su manifestación en una obra original y auténtica.

Io. Escúchese la Sonata en LA menor, K. 3 Io (I778), interpretada por Ronald Brautigam: https://www.youtube.com/watch?v=rEaIu8zzils

I I. John Cage, Silence (Middletown CT: Wesleyan University Press, I96I), 64. 


\section{Silvestre intérprete, Revueltas creador}

Silvestre Revueltas (Santiago Papasquiaro, I899-ciudad de México, I940) estudia violín desde niño y con ro años presenta un recital en Guadalajara; continúa con el instrumento en la ciudad de México y en Chicago pule su formación como violinista con Leon Sametini y Otakar Sevcík; enseña en el colegio de música de San Antonio, Texas, y da un concierto con el "Guarnerius fechado en 1684 "I2 que le presta un rico estadounidense hasta retornar a México en 1929 y ser profesor de violín en el Conservatorio. En su primera obra integra dicho instrumento con el piano en varias obras breves y entre 1929 y 1932 amplía su horizonte de las cuerdas con Cuatro pequeños trozos para dos violines y violonchelo, cuatro cuartetos, la primera versión de Cuauhnábuac para orquesta de cuerdas, Madrigal para violín y violonchelo y Tres piezas para violín y piano. ${ }^{\mathrm{I3}}$ Nuevos retos descubren nuevas luces de su ingenio: improvisa en la radio la voz del primer violín en cuartetos en ciernes cuyas voces define en partitura para hacerlas tocar por su camarada en la izquierda, el exiliado ucraniano Jacobo Kostakowsky, compositor y ex alumno de Sevcík, y con Higinio Ruvalcaba, violinista y compositor de una inventiva inédita ${ }^{\mathrm{I} 4}$ con quien además comparte capacidades de virtuoso y de goce del albur para controlar el disparate musical, illinx mexicano que lanza la moneda al aire y desafía a la suerte. El juego consciente de Revueltas con sus dotes es parte del riesgo y la pericia en que gusta regodearse; rebosa en inteligencia, intuición y talentos — violinista, pianista, profesor, director de orquesta, compositor y ensayista, por cierto no sólo musical— que músicos y público reconocen con unanimidad hasta convertirlo en leyenda. Si al inicio aborda al violín un espinoso repertorio ajeno o si coloca su instrumento por encima de un grupo de alientos y percusión en la Toccata, sin fuga (1933), pronto se harta — "no me interesa posar de virtuoso [...] me he dedicado a

I2. Robert Parker, "Revueltas in San Antonio and Mobile", Revista de Música Latino Americana 23, núm. I (primavera-verano, 2002): II6.

I3. Julio Estrada, "Voz de las cuerdas", cap. III, en Canto roto: Silvestre Revueltas (México: Universidad Nacional Autónoma de México-Instituto de Investigaciones Estéticas/Fondo de Cultura Económica, 2013), 68-85.

I4. Julio Estrada, "Higinio Ruvalcaba (1905-1976)", Humanidades, núm. 2 I8 (3 de octubre, 200I): I y I8. Jalisciense, estudia el violín con un mariachi —incluso como zurdo-y luego deviene el concertino de la Orquesta Sinfónica Nacional y primer violín del Cuarteto Lener, que en 1937 se funda en Budapest y cuyos miembros se exilian en México. 
la composición y dirección de orquesta, una pose mejor, quizá”. Is Cerca del final de su estancia en los Estados Unidos y no sin agobio, Silvestre comienza a dirigir en Alabama y a su retorno a México asume la dirección de la Orquesta del Conservatorio, asciende a subdirector de la Sinfónica de México y más tarde a director de la Sinfónica Nacional; desde el podio crea un foro para la música contemporánea en un ejercicio cotidiano que nutre al creador de ensayos innovadores y experiencias auditivas.

En San Antonio y en Chicago, siete años de formación compositiva, una buena dosis de juicio autónomo y un encierro de tres años más en México en busca de la voz lo llevan a la forja de su estilo en Música de feria $;{ }^{16}$ de ahí parte hacia una música cuya virtud es la nitidez confiada de lo pueblerino, melancolía ligada a la vivencia del niño que escucha el vestigio de bandas y orquestas decimonónicas, que llegan a México con el efímero Segundo Imperio y se trocean en localidades apartadas del país como su natal Santiago Papasquiaro. Aquella fragmentación ruinosa es parte de la enjundia campesina que conoce e integra al imaginario musical desvelado en Ocho por radio $-8 \times \sqrt{ }$, fórmula matemática con humor para el despiste - cuya torpe melodía inicial se tropieza en polirritmias que hacen desbarrar la armonía y maridar timbres en un azar de residuos; el rompecabezas se opone al nacionalismo y desmiente lo pintoresco para, en cambio, publicar el fondo dramático de lo popular, la quiebra del raigambre agreste y su despiste ante el emerger de una sociedad moderna, que no repara en aquellos ocho músicos que malogran el engrane -clarinete, fagot, trompeta, percusiones, un par de violines, violonchelo y contrabajo - de la ayer bandilla de quiosco, mercado o cantina, hoy enclaustrados, por radio. Revueltas retoma la picardía de Haydn que da al patrón aristócrata sorpresas y adioses sinfónicos para hacer irrumpir voces perdidas, subversivas o arcanas en una música cuya evolución es un enredo del cual escapan instantáneas en desbandada.

La impureza, imperfección y tosquedad son tela y trazo del mensaje que Silvestre transmite al mexicanismo del mural posrevolucionario; su estridencia indócil no suscribe la endogamia imperturbable del raso nacionalismo: Revueltas descubre al oído las rasgaduras de lo feo cuando Ponce reviste en con-

I5. Silvestre Revueltas, Silvestre Revueltas por él mismo. Apuntes autobiográficos, diarios, correspondencia y otros escritos de un gran músico, comp. Rosaura Revueltas (México: ERA, I989), 29.

I6. Julio Estrada, "Voz de las cuerdas", cap. III, en Canto roto: Silvestre Revueltas, 68-85. 
cierto lo bello, o se asume callejero entre la plebe frente a Chávez que entrona su música Proletaria desde el poder del Estado. ${ }^{17}$ En el primer lustro de los años treinta, quizá sólo en la pintura de David Alfaro Siqueiros se aprecie una búsqueda con alguna coincidencia con Revueltas y por fuera de lo ordinario: captar el desorden mediante la novedad en la estructura y en la materia para lograr en el lienzo el "accidente controlado", aporte del nuevo arte mexicano con mayor impacto en la pintura moderna - Jackson Pollock- que en el enclave cultural del muralismo, donde el dogmático Siqueiros exagera la gravedad del tono. ${ }^{\text {I8 }}$

A más del sentido escénico con que incursiona en música para ballet y pantomima o el gracejo adquirido en la pantalla como pianista de una peligrosa cantina, Silvestre Revueltas abreva en la libertad cinematográfica con una desenvoltura que logra como acompañante de películas mudas en los Estados Unidos para una década después dominar en México dicho territorio _ ¡Vámonos con Pancho Villa!, Redes o La noche de los mayas - y expandirlo a una obra que cobra mayor autonomía estética con Itinerarios; Planos, danza geométrica; Esquinas o Ventanas o refleja incluso métodos de edición fílmica mediante secuencias en paralelo, como la del cazador y la culebra en Sensemayá. ${ }^{19} \mathrm{El}$ cine revoluciona las costumbres al resultar más directo y de menor foro que la sala de conciertos o el escenario de la ópera; su resta de protocolo implica en Revueltas tomarse menos en serio para reaccionar con certeza en cada contexto y explorar también nuevos caminos. El escenario y la escena en su conjunto son el foro para sentar plaza de una conducta social y un irrespeto por la formalidad, chunga incluso de la cual no libra a su persona, como transluce la nota a Colorines: "Música de chirridos, dislocada [...]. Con un poco de imaginación, o [...] mucha, romántica [...] de un definido carácter mexicano [...] irónica, ruda, tierna, tal vez hasta un poco dolorosa." ${ }^{20}$

I7. Julio Estrada, "Revolución cultural: música de México", en Canto roto: Silvestre Revueltas, 23-43.

I8. Véase como ejemplo en Siqueiros, La tierra vista desde la estratósfera, acrílico sobre masonite, I971, 96× I20 cm, Sala de Arte Público Siqueiros, ciudad de México, en http:// www.molaa.com/Education/Folleto-de-Siqueiros-(sp)/paisaje-cosmico.aspx

I9. Julio Estrada, “Técnicas composicionales en la música mexicana de I9Io a I940", en La música de México, I. Historia, 4. Periodo nacionalista (I9IO-I958), ed. Julio Estrada (México: Universidad Nacional Autónoma de México-Instituto de Investigaciones Estéticas, I984), I33-I6I.

20. Silvestre Revueltas, catálogo de sus obras, comp. Roberto Kolb (México: Universidad Nacional Autónoma de México-Escuela Nacional de Música, I998), 35. 
La sustancia popular es parte del universo de Revueltas desde sus inicios, cuando sin fachadas de ningún orden integra a su música la voz común y corriente, como el pregón campesino que ofrece con candidez Tierra pa'las macetas o el cartel urbano del Afilador, armonioso desliz de arriba abajo y vuelta arriba de la flauta de pan - acaso su repertorio al violín en la Primera Exposición Estridentista de 1924 en El Café de Nadie de la ciudad de México. ${ }^{2 \mathrm{I}}$ Extroversión de los mundos urbano o rural, esos primeros pasos remiten a Les cris de Paris o Les oiseaux de la chanson que revela el encanto emergente de una sencilla materia sonora en Janequin; entonces la iglesia deja de ejercer su poder total sobre el coro y éste se convierte en recipiente de un babel de pregones, gorjeos o trifulcas — La bataille_; también en el aquí y ahora de la posrevolución mexicana que posterga la abstracción y la pureza al borrar el recato en el canto y abrirse a la licencia del abucheo, el silbo o el improperio. La pauta de esa nueva y antiquísima música popular acepta el descuido sin escame, donde error y distracción son peripecia que rueda con tino en el momento inesperado: se acabó la sinfonía y con ella el concierto, la belleza es permisividad. El alejarse de la música como arca preciosa encerrada en la ingeniería de sus mecanismos, el desprendimiento del yo manantial único del cual supuestamente emana lo musical y el reverdecer con voces incluso roncas y broncas separan a Revueltas del puritanismo que estorba al proyecto de compartir las aperturas del arte nuevo: "La civilización en nuestro mundo actual significa doblez, intriga [...] que sólo tratan de ocultar la perfidia y la deshonestidad. [...] La 'civilización' es refinada y sucia [...] es mierda destilada, embotellada y de curso legal." ${ }^{22}$ La reflexión contrasta con el tono solemne del artista y el intelectual mexicano de entonces, cuya exagerada formalidad no sólo impide el contacto directo con los otros sino sirve de muro de contención ante una sociedad cuyo caos opta por abstraer, contradicción inherente a un ámbito en el cual conviven con desigualdad el vestigio vivo del mundo campesino prehispánico y el mundo moderno en un insólito cruce de comunidades. Revueltas mantiene la señal de una lucha — “ya hoy es mañana y no podemos esperar siglos hasta un quimérico mañana que ya es hoy" — ${ }^{23}$ para que el arte no sea distinto de todos y sin el antifaz nacionalista-indigenista

2I. Carla Zurián, Fermín Revueltas. Constructor de espacios (México: RM/Instituto Nacional de Bellas Artes, 2007), I32.

22. Revueltas, Silvestre Revueltas por él mismo, I 7 .

23. Revueltas, Silvestre Revueltas por él mismo, 193-196. 
dé la cara en el crear; la música no es engaño y no debe prescindir de la rusticidad que deje apreciar al oído la fractura de su factura, componente propio del tiempo efervescente vivo y factor esencial de su estética popular. La ñoñez de una escasa facción académica local pretende criticar la formación musical de Revueltas, quien, sin atender reproches, mantiene con porfía el rumbo y deja entrar a escena una caterva orquestal maleducada que percute con ritmos necios y obstinados, anuda collages con harapos y desmadra planos instrumentales.

Revueltas fragua un realismo musical de ficción diferente de la prudencia cultural adoptada por sus colegas contemporáneos y se empapa de la inexactitud caótica del país, esa fractura hasta la médula que Silvestre modela con oreja impía y Neruda rememora al evocar el país "florido y espinudo, seco y huracanado, violento de dibujo y de color, violento de erupción y creación", ${ }^{24}$ al que alaba tanto como critica - "México está en sus mercados, no en las guturales canciones de las películas" —, ${ }^{25}$ estampa que desoye al país insustancial de quienes aspiran a destacar su reputada firmeza a contracorriente del mundo pueblerino y de metrópoli que se descubre en "la plaza", centro remoto de lo mexicano que despierta todos los sentidos: la frutería que irradia colorido, la carnicería que exhibe vísceras y pulmones sombríos, la venta de jumiles y chapulines vivos, el yerbero que pregona curaciones quiméricas, las plantas de ornato y la florería, las taquerías y merenderos que jasmás niegan tortilla al mendigo, el sature bullicioso de cantos y conjuntos, todo salpicado de olores de corral, pescado enrarecido y fermento pulquero.

El desdén revueltiano por la circunspección - Tragedia en forma de rábano, no es plagio; Música para charlar u Ocho por radio- no es demasiado distante de la pulla del militante de izquierda y sin más partido que la llaneza del pueblo; el paso del escenario a la protesta pública carece en Revueltas de frontera para aportar con singular individualismo una lección artística de congruencia dentro de un legado que arrumba el desoír de la censura: consigna obrera —Porras, "sindical única" - himno antifascista - México en España-, melodía militante — Un canto de guerra de los Frentes Leales-, sainete político - Éste era un rey_ o marcha combativa _ Frente a frente. El canto de la "Adivinanza” en la segunda versión de esta última — “ya se estira ya se encoge, ya se jala de la piocha, el clown de las barbas de chivo; ya

24. Pablo Neruda, Confieso que he vivido, Memorias (Barcelona: Seix Barral, 1974), 69.

25. Neruda, Confieso que he vivido. 
se para ya se sienta, ya no piensa más que en su cuarta senil" - ${ }^{26}$ se parodia en el desfile con una carreta: dos muñecos, Hitler y Mussolini, y un gorila enjaulado al que se le gruñe con acento entre cubano e infantil — "Triki, triki, triki...": Trotski, el de la "cuarta senil" Internacional. ${ }^{27}$ Silvestre representa a la $\operatorname{LEAR}^{28}$ y dirige la marcha de una música que invita a hacer escarnio del enemigo: el redoble del tambor militar fondea a un quinteto de metales cuyas dos trompetas, pelo en pecho, expulsan una trompetilla al cierre de cada estrofa de un corrido cuya letra se lanza sin miramientos a todo pulmón. Narra la escena el cubano Juan Marinello, presente el primero de mayo en el Zócalo: "Se metió en la multitud, con su chamarra de cuero abierta y la redonda cara congestionada por el esfuerzo y el sol. Adiestraba en el canto [...] a la gente de su cercanía; después entraba en un pequeño automóvil y marchaba, con un grupo de iniciados hacia otra parcela de la multitud, que sólo abandonaba cuando todos habían aprendido la consigna musical." ${ }^{29} \mathrm{El}$ grito de furia en Frente a frente condena a muerte al enemigo - "Mussolini, Franco, Hitler y pandilla”- y hace escarnio de Trotski — “¡Ah qué bolas tienes! ¡Con ellas te entretienes!"- ; al cerrar la frase, una trompetilla de trompetas regüelda el acorde, feo encanto que legitima la tirria con una distorsión forzosa ajena a toda finura y mesura artísticas (fig. 2).

\section{Una naturaleza impura}

El bando formal del Estado mexicano posrevolucionario sobre la música nacionalista creada entre 1920 y 1960 ensaya integrar a fortiori lo poco que se difunde de Revueltas dentro de la corriente nacionalista, incluso indigenista, escuela y secuela de Carlos Chávez cuyo incontinente estilo orquestal estadounidense tiene en Galindo, Moncayo o Sandi el refrendo sistemático de lo superfluo. El nacionalismo oficial indigenista y mestizo se asume modernista

26. Julio Estrada, "Camarada solitario", cap. IV, en Canto roto: Silvestre Revueltas, 86-I I5.

27. La "Adivinanza" coincide con el largo periodo en que la izquierda mexicana confía en Stalin sin entender ni suponer el final trágico de Trotski, quien llega a México a principios de 1937 y es asesinado en Coyoacán en el verano de I940, semanas antes de morir Revueltas.

28. Liga de Escritores y Artistas Revolucionarios, de la cual Silvestre Revueltas es secretario en 1937.

29. Juan Marinello, Imagen de Silvestre Revueltas (La Habana: Sociedad Cubano-Mexicana de Relaciones Culturales, I966), 23. 

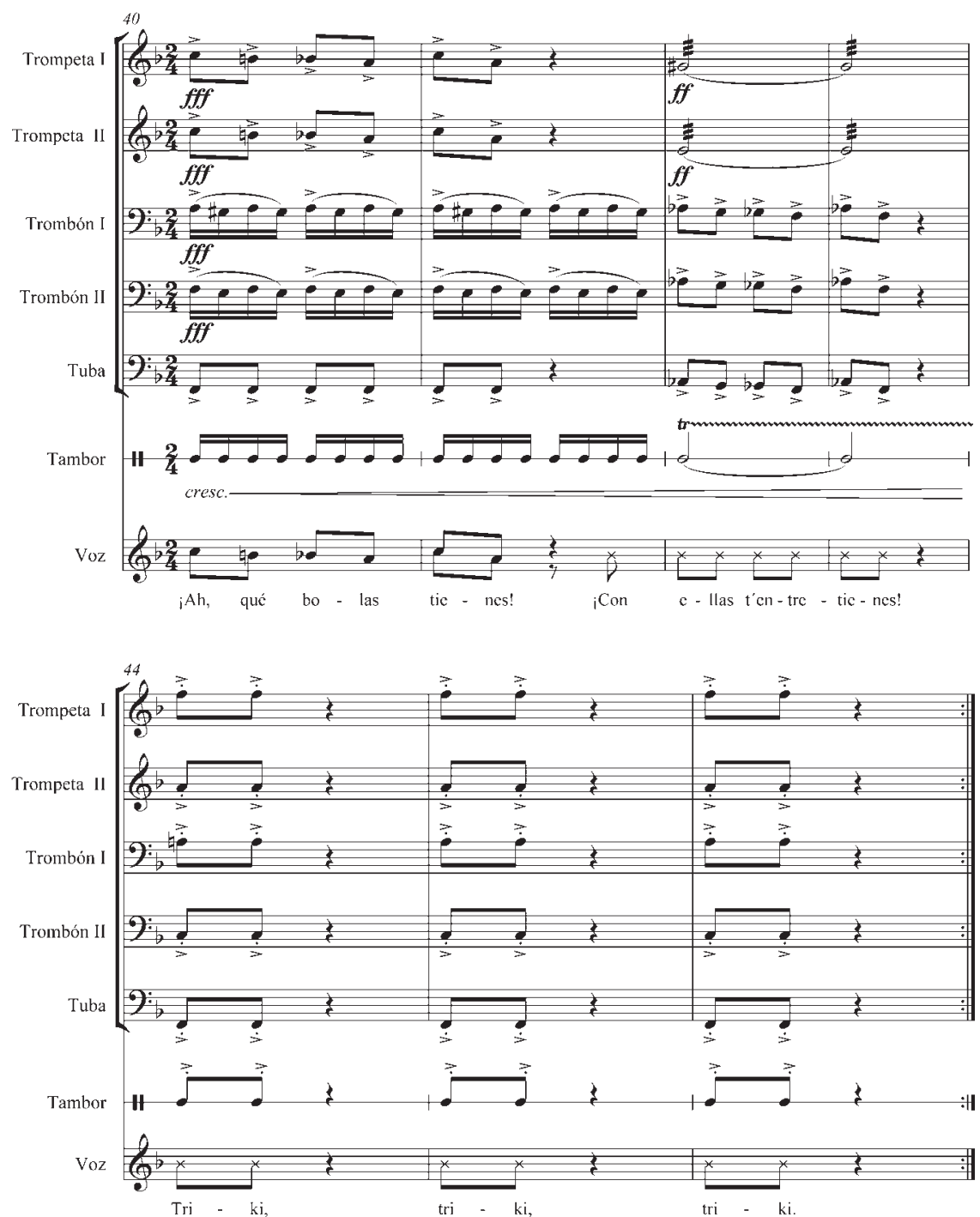

2. Silvestre Revueltas, Frente a frente, fragmento final, "Adivinanza", segunda versión de la obra. 
aunque no abandona la premisa decimonónica de Manuel M. Ponce —ennoblecer al original con armonía, contrapunto e instrumentación-y continúa con un componer cuya tintura, lustre y adorno denuncian el fondo: orquestar es enmascarar la creación sin rostro. Una señal similar marca el camino al arte mural cuyos semblantes hinchados, entre manifiesto y caricatura, son estrategia oportuna para alegrar la causa política y el duelo, simbolismo estatuario de una imaginería artística a ultranza —el mexicaneo- cuyo escenario no logra ocultar la tramoya del Estado. El aire épico de la apuesta institucional posrevolucionaria fragua después del embrollo implantar una hegemonía que describe la realidad con pureza, idealismo y aires de perfección. Con franco y anticipado antagonismo, sin obedecer a nadie Revueltas impregna su música con rasgos de un estrago vital que evoca la posrevolución en solitario convencido de que la gente común y corriente porta con hondura verdades que desvelan el falso discurso. Silvestre no habla de su zozobra, la vive en la indigencia en la calle Mixcalco del barrio de La Merced al lado de amigos cargadores con quienes se encierra para compartir el tonel de pulque en la dirección del conservatorio y al día siguiente ofender desnudo en el patio ante profesores y estudiantes la jura oficial a la bandera. La burla es reclamo privado en público al afeite que se expande en todos los ámbitos con la pretensión de imponer como nuevo catequismo el patriotismo estatal revolucionario. Los desaires al mundo no son veleidad: en la miseria pierde a dos de sus hijas pequeñas, también a Fermín el hermano que le sigue, mientras a José, el benjamín, se le recluye en las Islas Marías por su ideario y su acción política; Silvestre mismo es perseguido en el trabajo hasta hacerle perder el empleo; se le encuentra desbaratado, dormido incluso a la luz del día en pleno Zócalo de la ciudad o se le deja de ver por semanas o meses cuando ahoga en alcohol la depresión obsesiva - revela Athos Campillo-y debe someterse al encierro psiquiátrico (fig. 3). ${ }^{30}$

El Silvestre niño inventor de música a "tamborazos en una tina" ${ }^{1}$ resurge maduro y esparce imágenes para dar voz a la escena popular y a la mirada íntima, como el montaje de contrasentidos que en Ocho por radio frustra la escucha abstracta y aviva la representación interior de instantes cuya ilación

30. Athos Campillo, "tamborazos en tinas de baño; perspectivas psicológicas de Silvestre Revueltas”, en Silvestre Revueltas, II Coloquio Internacional (México: Universidad Nacional Autónoma de México-Escuela Nacional de Música/Consejo Nacional para la Cultura y las Artes-Instituto Nacional de Bellas Artes-Fondo Nacional para la Cultura y las Artes, 28 de agosto, I998), programa de mano, 44.

3I. Revueltas, Silvestre Revueltas por él mismo, 28-29. 


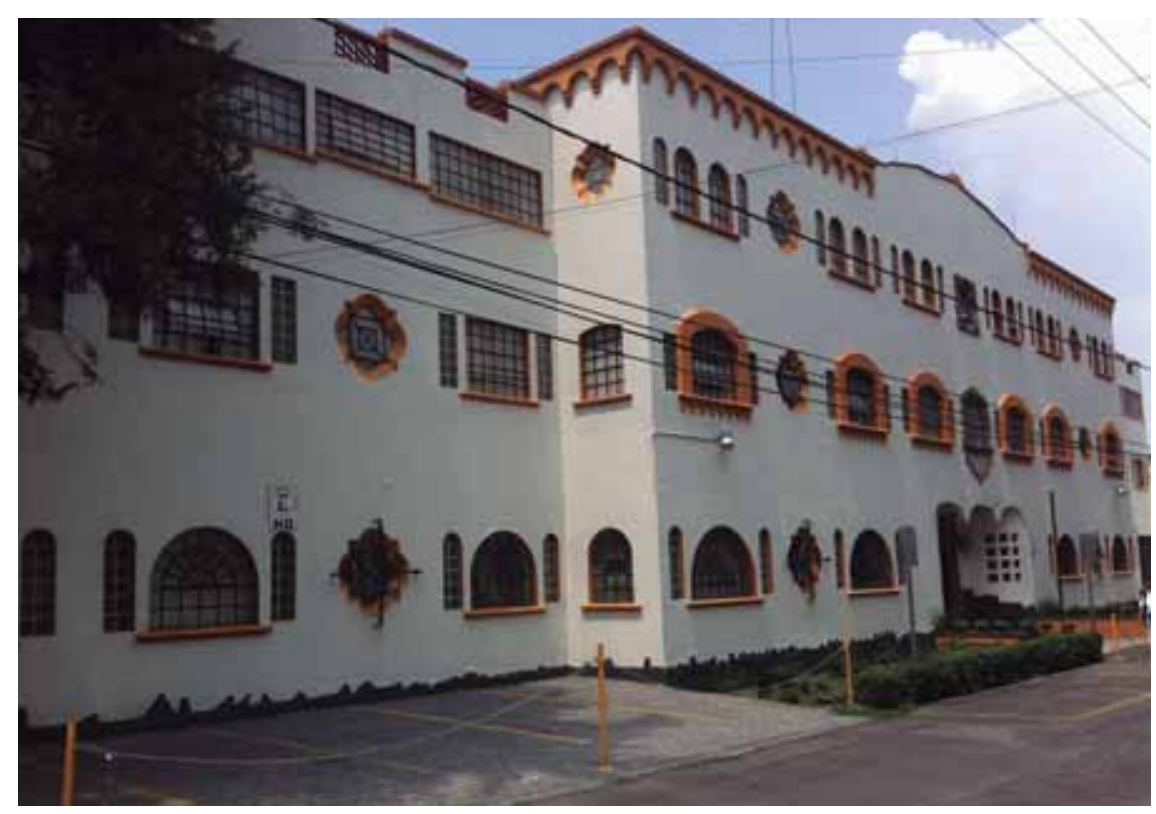

3. Clínica del doctor Falcón, ciudad de México. Foto: Julio Estrada.

en secuencia nos pierde; el piso desaparece y el oído cae en el anzuelo del espacio contiguo hasta hacer que humor y desamparo muden a la par. Armar la historia es inaplicable cuando la sensación perceptiva remite al corte abrupto de una arquitectura laberíntica, la avería topográfica de la partitura: nada deja aprehender una forma cuyo surrealismo estridente el furtivo Revueltas no revela sino sólo lanza en añicos que dejan huella de aquella cicatriz, que en lo privado es vieja herida (fig. 4).

La plasticidad entre espontaneidad y freno que da Silvestre a su obra es la estridencia, ocurrencia y estropicio de un México plural a interpretarse desde dentro de la música, sin ataduras al escrito que olvida la entraña popular; el modernismo revueltiano sirve para capturar lo desastroso mediante una escritura que recoge el error en la altura y el ritmo de la melodía, que opta por la disonancia politonal de armonías y contrapuntos confundidos por la polirritmia, que disparatan la forma con el recorte y el pegote del collage o que desbarata el buen porte cuando trepa al flautín en la tuba, todo ello onomatopeya que dilapida en el ambiente un rostro de todos conocido, el ruido mexicano. Dentro de éste se implanta una pirámide de ritmos negroides, el ostinato de 
4. Silvestre Revueltas.

Foto de autor no identificado (ca. 1939-1940) con dedicatoria — “para J. Kostakowsky”. Acervo Jacobo Kostakowsky, Archivo de Músicos Disidentes Mexicanos, Biblioteca Justino Fernández, Instituto de Investigaciones Estéticas, UNAM.

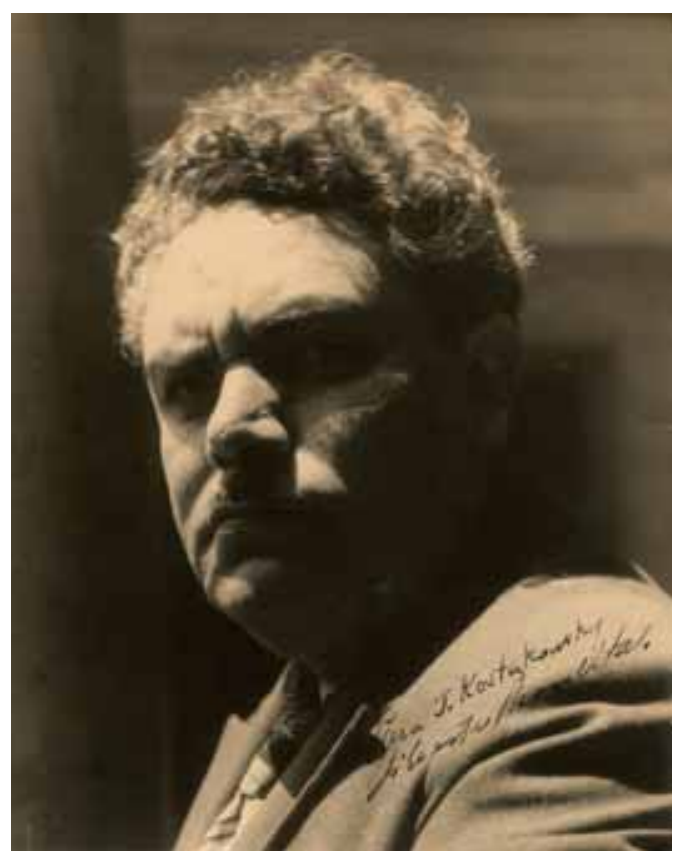

Revueltas, cuyo aire convulso descubre en secreto al oído el diálogo trágico entre la compulsión volcánica y la depresión crónica que avanzan implacables hacia un triunfo marcado por el desaliento.

Las interpretaciones modernas tienen el ánimo de reconocer internacionalmente la obra de Revueltas con versiones de incontestable calidad musical y flamantes técnicas de grabación que avizoran la naturaleza creativa del mexicano; ejemplos de ello son en el extranjero, desde Serguéi Kusevitski hasta David Atherton y Esa-Pekka Salonen, y en México, de Luis Herrera de la Fuente a Eduardo Mata y Enrique Diemecke. La mayoría de dichas interpretaciones se propone una clara articulación de las melodías, una precisión rítmica y una transparencia en el color instrumental que dan a su Revueltas un aspecto mucho más fiel a la escritura musical en abstracto que al fondo característico del autor, su enmarańado mexicanismo. Baste vigilar el papel del flautín en las grabaciones de Atherton, cuyo aire puntual lo asocia a su sonoridad en la banda militar y lo distancia del gozoso melisma infantil en El tecolote (1932, versión II), El renacuajo paseador (1933-1936), y en el "Baile" del Homenaje a Federico García Lorca (I936); esa tonada del flautín se lee en 
lo innato del hermano que percibe José Revueltas: “tierno, lleno de júbilo, enardecido por la alegría de vivir [...] transparente como un niño, con una candidez interior tan inmaculada..."32 A la antípoda, la tuba en la mayoría de aquellas grabaciones da la imagen de una sabia y clara pronunciación cuyo brillo marcial recuerda el arma de rango potente, en contraste con el rostro grotesco que adquiere en el Revueltas de la gracia y el tono épico y remoto en la tragedia. ${ }^{33} \mathrm{Y}$ sin embargo, las viejas grabaciones de Luis Herrera de la Fuente - decano por décadas al frente de una institución orquestal cuyo origen remonta a Chávez y a Revueltas - cuentan con la ventaja de aportar la experiencia de músicos, hoy desaparecidos, que actúan bajo la batuta o son amigos cercanos de Silvestre. Emblema de esa memoria contenida en las viejas versiones de Herrera es Rosendo, titular de la tuba en la Sinfónica Nacional hacia la década de 1960 y corpulento moreno quizá con 20 o 30 años al morir Revueltas: en el sonido de este personaje — acaso de la Oaxaca vivero de bandas - pueden anidar la lección al oído del autor o la voz que en Sensemayá inspira al instrumento mítico de opaca tenebrosidad del que emana la reverberación oscura de una bóveda, más que metal, barro cocido a baja temperatura. Personajes recónditos del Revueltas íntimo, el flautín infantil y la fuerza arquetípica de la tuba autorretratan, a conciencia o sin ella, el carácter dual que lo mismo retoza con chispa protagónica o bufa con tono lóbrego y secreta ironía: el maridaje clandestino flautín-tuba es gozosa broma no enunciada del niño y el elefante, el jilguero y el tonel pulquero. ${ }^{34}$ También ebriedad con guiño bergsoniano e infortunio insondable (fig. 5)..$^{35}$

32. José Revueltas, “Apuntes para una semblanza de Silvestre Revueltas", en Las evocaciones requeridas (memorias, diarios, correspondencia), t. II, vol. 26 (México: Era, I987), 301.

33. En retrospectiva es igualmente obvio cómo a pocas semanas de morir Revueltas se intenta concluir La coronela para estrenar el ballet de Waldeen; Candelario Huízar orquesta la partitura perdida en el desaseo de la biblioteca de la sinfónica oficial en tiempos de Carlos Chávez en el gobierno de Miguel Alemán; un par de décadas más tarde José Limantour y Eduardo Hernández Moncada vuelven a naufragar en el proyecto de pastiche: la libertad en el juego de colores, el jirón de la ironía o la desproporción infalible para hacer que aparezca el turbador espectro de la tuba en el inframundo son inapreciables. El mexicano ceremonioso que ensaya un luto falso obstaculiza la recuperación de la obra legítima, en contraste con lo que sería escuchar con sencilla justicia historicista La coronela inconclusa en la versión última y original del autor al piano.

34. Combinación en El renacuajo paseador, versión II, ballet pantomima para marionetas -flautín, clarinete pícolo, clarinete, dos trompetas, trombón, tuba, percusión, ocho violines y dos contrabajos-_- o en Homenaje a García Lorca —-flautín, clarinete pícolo, dos trompetas, trombón, tuba, percusión, piano, cuatro violines y contrabajo.

35. La frescura y alegría que se captan en una fotografía poco conocida de Revueltas es 
5. Silvestre Revueltas. Foto de autor no identificado, $c a$. 1936.

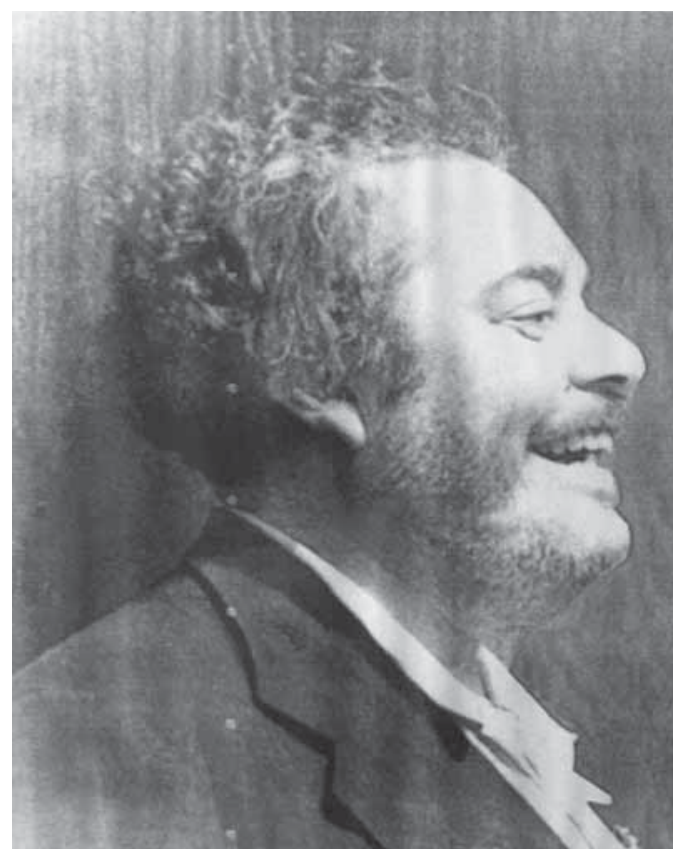

La mera correspondencia con la partitura original a la cual aspiran las versiones modernas de Revueltas pende de una estética cuyos créditos de buen lustre distan de abismarse en la vivencia que funda la música: la aparente abstracción de la Danza geométrica o el vigor de Sensemayá conducen a interpretarlas con idéntico talante modernista para realzar su belleza disonante y percutiente como la materia musical pura de una mirada convexa que mengua la irrupción del desasosiego de una u otra criaturas, ambas germinación del espasmo, ambas pesadilla. Mientras más perdura la prescripción de formular la imagen del compositor nacionalista, menos se esboza el tono en verdad popular del Silvestre mexicano, ni tampoco se descifra al Revueltas que explora en el constructivismo abstracto - Planos - o en el expresionismo - Cuarteto de cuerdas No. 3- y que con penetrante sentido linda en el drama dostoievs-

excepcional: una sonrisa raramente observada en otras imágenes, la barba de varios días y el pelo desordenado que cubre parte de la oreja; en comunicación personal Eugenia Revueltas relata que así recuerda a su padre, al que le pedía agitarse el cabello con gestos de humor. La fotografía es una copia de otra copia amplificada y enmarcada en el Auditorio Silvestre Revueltas de la Facultad de Música de la Universidad Autónoma de Nuevo León. 
kiano, un cariz de la dolencia psíquica realzada hasta hoy. ${ }^{36}$ La interpretación pulcra deriva en una homogeneidad más vivaz que vital, enérgica que frenética, armónica que ruidosa, un todo cuyo acople impide dar con la contraseña del desbarajuste. De extraviar la identidad heterogénea de Revueltas se anulan el juego, el conflicto o la violencia compulsiva que se fusionan en esa trama íntima con la cual se le ve actuar frente a la orquesta y trabar vínculos de intuición en torno suyo, certeza declamatoria como marca de su obra en el cine, el ballet, la pantomima y la sátira política.

Pensamiento y sentimiento escénicos son herramienta inconfundible de la expresión musical revueltiana, a su manera cercano al mundo sinfónico mahleriano, novela sonora cuyo mensaje se auxilia de la onomatopeya y de otros músicos para nutrir así la paleta por donde se infiltra un narrar sin palabras. Revueltas comparte con Mahler ese fondo de ficción sonora y ese narrar per se, íntima propensión al desahogo imbuida de pasión escénica, incluso sin argumento concreto, como revela su testimonio sobre una de las primeras producciones orquestales, Ventanas (I93I): "cuando compuse la música tal vez intenté comunicar una idea definida; ahora, después de que han pasado tantos meses, ya no me acuerdo qué era". ${ }^{37}$ La velada historia aquí referida no es el significado sino el significante, esa necesidad ineluctable de vivir el ambiente mental de la escena que estimula la creatividad y da fiebre a la música, faceta del artista plural duranguense cuyo talento literario coyunta con lo sonoro: "Un sollozo como un vómito de sangre y lágrimas [...] y este sonido penetrante tiene ecos [...] solloza todo dentro de uno. Cada nervio es un sollozo tendido, abierto como un caudal de llanto [...] de noche [...] Llanto de niño, llanto de hombre, todo es llanto que nada puede enjugar."38

Según una interpretación reciente de la música de Revueltas sobre el poema de Nicolás Guillén "Sensemayá, canto para matar a una culebra", ${ }^{39}$ en la música anida el "triunfo del bien sobre el mal"40 para subrayar la percepción ética que ronda en la mente del músico en aquel momento de guerra civil en

36. Julio Estrada, "Totalidad desarmada”, cap. II, en Canto roto: Silvestre Revueltas, 44-67.

37. Sergio Fernández Bravo, "Silvestre Revueltas: 'no tengo prisa”, en Sensemayá, The Music of Silvestre Revueltas (The Sony Classical, I999), cuaderno de notas del disco compacto, 29.

38. Rosaura Revueltas, "Silvestre", en Los Revueltas (México: Grijalbo, 1980), 84.

39. Nicolás Guillén, West Indies Ltd. (La Habana: Imprenta Ucar, García y Cía., 1934).

40. Ricardo Zohn Muldoon, "La canción de la culebra: el Sensemayá de Revueltas", en Silvestre Revueltas, sonidos en rebelión, eds. Roberto Kolb y José Wolffer (México: Universidad Nacional Autónoma de México-Escuela Nacional de Música, 2007), I88-22I. 
España: destruir al maligno que encarna la culebra, como en el mito judeocristiano, es defender el bien. Más allá del reduccionismo alegórico, la proposición contrasta con el acote de la obra al rito lucumí-yoruba afroamericano ${ }^{4 \mathrm{I}}$ y da pie para otra hipótesis, la evocación del drama que vive Revueltas durante la creación de Sensemayá: acoso de Chávez y pérdida del trabajo, ${ }^{42}$ celos pueriles por Ángela la esposa —-indisociable de la vacilación ante la propia obra-, depresión crónica y encierro psiquiátrico, sentimiento de fracaso y derrota, y esa temprana y asidua premonición de la muerte. La angustia, el temor y el abismo íntimos avivan el lento resonar de la tuba mirum de Sensemayá cuando canta su destino por encima de la canícula silenciosa del tam-tam y el oscuro fondeo del clarinete para ensartarse en el bordón cáustico del fagot, pasacalle sin fin que mutila el ocho y cicatriza la anómala cola del siete. La línea que da ritmo insistente al poema - ma-yom-be-bom-be-mayom-bé- se reconoce en el inclemente pulso de los violines $(v----v v-)$ y se enhebra al hostigar del verdugo a la culebra — “¡dale ya!” — , colisión de ciscos que se encaraman en un correoso reloj piramidal donde rezos y cantos tejen lascivamente una maraña abrasadora. Sensemayá deviene el habitáculo de Revueltas: es él la culebra a la cual acorrala una ponzoña métrica cuyo amarre hipnótico engaña hasta la caída — "Sensemayá, la culebra... Sensemayá, se murió”- ahí no hay triunfo alguno, el orden del estruendo es el tormento, y su extinción en el silencio no deja de aludir al canto: "la culebra muerta no puede silbar".

El señoreo inconsciente de la contradicción íntima en el mundo revueltiano es conmovedor en la macroforma del Homenaje a García Lorca —escrita en 1936 a pocos meses del asesinato del poeta en Granada-, cuyos "Baile" inicial y alegre "Son" en ambos extremos realzan la antinomia de la tragedia central, el "Duelo". Velasco Pufleau aporta una perspectiva novedosa y esclarecedora de la insólita cábala —mi traducción—: ${ }^{43}$

4I. Julio Estrada, "Técnicas composicionales en la música mexicana de I9Io a I940", en La música de México, I33-г6г.

42. Julio Estrada, "Chávez y Revueltas: los eclipses", en Canto roto: Silvestre Revueltas, cap. V, II6-I52.

43. Luis Velasco Pufleau, "Musique, antifascisme et autoritarisme: l'œuvre de Silvestre Revueltas dans le contexte de la Guerre civile espagnole”, tesis de doctorado (París: Université Paris-Sorbonne, 20II). 
Revueltas hace referencia a la muerte de García Lorca y muy probablemente también a la fiesta de muertos de México; ${ }^{44}$ [...] construye el Homenaje a [García] Lorca en forma de tríptico: una primera parte — "Baile” — de carácter alegre y jocoso — que puede referir a las calaveras populares—45, una segunda — "Duelo" — representando la muerte y el duelo y una tercera — "Son" — que podría representar la victoria de la vida sobre la muerte. [... Revueltas] confirma la referencia a la fiesta de muertos y dedica implícitamente la obra a su hija fallecida unos meses antes, al fechar la composición del segundo movimiento el I de noviembre de $1936 .{ }^{46}$

\section{Código, memoria, trance}

El código escrito en música fija comunica e incluso sirve para analizar lo que suena, parcialmente, porque la escritura puede no envolverlo todo ante una memoria rica en articulaciones, una tradición libre en la práctica o sencillamente creatividad, como antes del siglo xx cuando se espera del intérprete intuición discursiva. Tal frescura en la usanza no logra instaurarse en la interpretación histórica moderna para adecuar el código al goce de la vivencia musical con formas más abiertas de ceñirse a la escritura, tema urgente en el proceso de comunicación de un repertorio al cual la imposición imperceptible de trabas estorba al sentido de la música. El desapego del público por la música contemporánea después del brío de su génesis resulta en ocasiones sensato si se escuchan el pretencioso sesgo con que se expone lo nuevo, con el consecuente vuelco hacia el repertorio antiguo y un interés mayor por el intérprete y su producción, hoy remplazo del parco futuro del compositor, voz primordial en otras épocas y sociedades.

La comercialización del fonógrafo genera una plétora de versiones en torno a una misma obra, con lo cual el intérprete tiende sin quererlo a fijar

44. N. de Velasco Pufleau: La noche del I de noviembre se consagra en particular a los niños muertos, los angelitos, mientras que el 2 de noviembre es la fiesta de todos los difuntos.

45. N. de Velasco Pufleau: Las calaveras son poemas populares de carácter anecdótico, irónico o satírico, escritos para la fiesta de muertos a la memoria de un difunto o, en algunos casos, de un vivo.

46. N. de Velasco Pufleau: Las fechas de composición no siguen el orden cronológico de los movimientos en los manuscritos existentes: I. "Baile" — I6 de octubre de I936-, II. "Duelo" — I de noviembre de 1936-y III. "Son" — I2 de octubre de 1936-, cf. Silvestre Revueltas: catálogo de sus obras, comp. Kolb. 
sus modelos mediante registros cuya distribución y predominio en el oído colectivo adquieren peso de marca en el gusto; pocos ejecutantes resisten la normatividad prevalente en la ejecución grabada para, en cambio, apegarse a la fertilidad creativa del concierto, como con Hans Knappertsbusch (I8881965), quien evita el ensayo para ofrecer en cambio la vida que corre en sus interpretaciones. Mientras, al cabo de numerosas décadas de convergencia alrededor de la versión musical, noción en boga, ésta deviene un código para la interpretación, objeto de tasación que aparta al oído de la memoria viva de la música y de su proceso creativo. En el repertorio musical de la segunda mitad del siglo xx la versión contrasta con la fijación musical en tanto que testimonio de recreación artística que dejan los autores de música mecánica, electroacústica y digital. Si bien es cierto que el autor ejecutor de su propia obra acomete un cambio radical en la tradición auditiva al acercarse al pintor o al escultor que borran a todo otro intérprete, los creadores más innovadores dejan por escrito su producción — véanse la partitura que complementa al rollo para piano mecánico de Nancarrow, la notación electrónica de Stockhausen o el gráfico digital con el cual Xenakis reproduce los datos-: la irradiación de percepciones del intérprete, incluso como autor, abre caminos a la escritura y sostiene con ésta un diálogo incesante.

De Revueltas el intérprete sólo queda lo que rememoran en testimonios escritos espectadores sensitivos — Octavio Paz, Elena Garro y José Revueltassobre quien improvisa o ejecuta su obra al piano, al violín o ante la orquesta; si al morir no desaparece su aura musical, acaso él mismo contribuye con su carácter a veces imprevisible o hermético al dejar como mensaje un silencio, al quizá no grabar una versión propia de su música. El silencio del Silvestre intérprete coincide con la libertad de su carácter; si su escritura es clara y autosuficiente, no incorpora necesariamente en ella todos los datos porque no aspira a la precisión de un modo absoluto: sabe como intérprete que tiene un contrato flexible con la partitura. Su irradiación de talento le da la ventaja de improvisar en vivo ante el micrófono o de llegar al podio con alcohol en las venas sin titubeo para dirigir airoso el programa orquestal; en vivo en el sitio mismo dicen que es aún más impresionante su huida de la depresión crónica y su posesión del duelo. Su Beethoven o su Stravinski no son mera actuación en público del conocedor que es de su oficio sino también comunión viva con la rabia y la violencia yacente en las voces de otros; al sonar a Beethoven sabe imprecar con voz propia y al sonar a Revueltas sabe retratar mejor que ninguno el yo que padece su música. 
Silvestre no coincide con la idea que se le intenta imponer imperiosamente para recuperar su obra bajo el perfil de una identidad superficial, todo ello forzado por la versión histórica oficial donde, sin adoptarlo como es, tan solo desea ajustarlo a un debe ser que, dentro y fuera del país, retarda al intento legítimo de interpretar una música proclive a la expresión íntima y popular: la mirada de Revueltas carece de la formalidad fervorosa del nacionalismo que exalta a un mexicano abstracto. En contraste con la parquedad derivada de la estética profesada por sus colegas, el vínculo recóndito de Silvestre con su oído transmite un afecto de tiernos tonos sin velo alguno - como en la "Canción de cuna" para voz y piano, en el "Baile" del Homenaje o al hacer que la gigante tuba cante en Troka "a la víbora de la mar" - y una emoción intensa que todo lo permea — el íntimo movimiento lento del tercer cuarteto, la violencia de Sensemayá o el sentimiento de pérdida en el "Duelo" del Homenaje. El propio imaginario musical revueltiano sueña con oír, ver y palpar su arte como "color, escultura y movimiento", 47 sinestesia que incita al ensayo de aproximarse con igual ramificación sensorial a Itinerarios o Planos, danza geométrica, donde la materia popular cede espacios a la abstracción — "arquitectura 'funcional' que no excluye al sentimiento [...] ritmo obstinado, siempre en marcha..." - ${ }^{48}$ hecha de visiones casi delirantes dentro de un arrebato telúrico al cual refiere el propio autor:

Todo es ritmo. [...] Mis ritmos son pujantes, dinámicos, táctiles, visuales [...] imágenes que son acordes en líneas melódicas y se mueven dinámicamente. [...] cuando se posesiona de mí la necesidad de dar forma objetiva, gráfica, a esos ritmos, sufro una conmoción biológica total. Es mayor que el esfuerzo del parto, no por la expulsión, sino por la manera de recoger el producto y llamarle con algún nombre. Esa conmoción me conduce a veces a la negación más absoluta de mí mismo. ${ }^{49}$

El estilo revueltiano, hecho de múltiples facetas, componentes o texturas — de la melodía popular mestiza al canto político, del ritmo indígena al negroide y la polirritmia, del desorden al ostinato-, fusiona el todo con un aire único, que requiere una escucha perspicaz para, con mayor profundidad que la acostumbrada, lograr la percepción de la obra. El cometido básico es

47. Revueltas, Silvestre Revueltas por él mismo, 30.

48. Revueltas, Silvestre Revueltas por él mismo, 21 2-213.

49. Revueltas, Silvestre Revueltas por él mismo, 32-33. 
urgente en los órdenes musical y musicológico para propiciar que una interpretación sensitiva haga inteligibles las esencias de esa música, que desde la muerte de su autor, no encuentran dueño que las legitime. Desvelar los procesos que la inspiran implica buscar otro centro y no senderos donde se pierde el sentido último; más que aplicar como receta el orden puro ante la partitura, resulta mucho más significativo escucharla desde la mente que insiste en la distorsión y ensaya a conciencia descarrilar alturas o ritmos con aires intrusos a su estructura, o desde esa "conmoción biológica total" que con manía repetitiva inconsciente pulsa y machaca ritmos y cantos. El repertorio revueltiano reclama del intérprete una audición interior inexplorada para, antes de que nada se escuche, impedir al oído continuar corrompiéndose con una memoria cuyo compromiso excesivo e insuficiente peso artístico sólo demora entender la aventura creativa que contiene el original. La aproximación al origen pide medir la coherencia potencial entre la realidad y su representación en la fantasía, si se entrevé que el contacto con el dato simple y llano puede nutrir al imaginario y proveer de nuevas visiones de la obra. La copia idéntica del objeto del deseo, primera solución, reduce todo a la fonología, mientras que el confrontar la materia original mediante una apertura a otras formas de recreación ofrece a una enseñanza estética similar a la del artista plástico que observa su modelo para ver y trazar la imagen con un modo propio. El músico limita tanto creación como interpretación al código escrito al seguir la tradición proclive a convertir todo a cifra y mantenerlo dentro de la estrechez del símbolo; ello, en contraste con la escucha que observa al objeto desde la perspectiva de la realidad.

El encierro permanente de la obra revueltiana en el ámbito formal del concierto sinfónico es quizá menos enriquecedor que el experimentar escucharla bajo condiciones aproximadas a su imaginario, por ejemplo, la modesta orquesta de pueblo capaz de reflejar en lo real aquel desastre que sensibilizaría más al oído que el manso aprendizaje del orden. Revueltas nutre su escucha de la cata de un universo campesino yaciente en el recuerdo arcano fundido a un drama privado, audición que cifra con la escritura a su alcance y, como en toda época, con herramientas aún en ciernes para permitir convertir de un trazo la fantasía en realidad. Buena parte de su propia faena como intérprete es la de infiltrar la percepción del creador regenerador del aquello mediante avíos certeros que le permitan desvelar el fin último de la obra, esa sustancia que no siempre queda por escrito - como el trastoque de Fischer, quien transgrede la partitura para transcender con la Patética la sordera de 
Beethoven. Interpretar a Beethoven o a Revueltas es impregnarse de la médula de sus vivencias y no sólo convertir la partitura en una música cuya claridad y transparencia borren el ruido inmanente al proceso de creación, nebulosa acaso ausente o apenas sugerida por la escritura, pero aún pendiente de intuirse por el imaginario que ensaya recobrar la esencia. Poner en la mira la interpretación de Revueltas pide la arqueología de su existencia social y de su psique como hermenéutica de cada página de su obra, opuesta a la pureza que se le asigna cuando lanza lava sin cesar durante una década y pone en juego sus ingenios para explorar vínculos entre la inflexión física del habla cantada campesina y el sordo rumor metafísico que asedia su mente: la tarea, vertiginosa para la dimensión temporal del destino del autor, apremia a la elucidación polisémica de un nuevo oído. \$

N.B. El presente ensayo, expuesto inicialmente en julio de 2012 en Roma, en el Congreso de la Sociedad Internacional de Musicología, se suma a otros seis escritos durante casi tres décadas en torno a la figura de Silvestre Revueltas, actualmente englobados en Canto roto: Silvestre Revueltas. 